\title{
Konya-Akyokuş Yöresinde Yetiştirilen Althaea Officinalis-Hatmi Bitkisinin Etanol Extractının Toplam Flavonoid Miktarı
}

\author{
Hayriye ALP \\ ${ }^{1}$ Necmettin Erbakan Üniversitesi, Sağlık Bilimleri Fakültesi, Fizyoterapi ve Rehabilitasyon Bölümü, Konya, Türkiye, \\ hayriyebalp@yahoo.com (Sorumlu Yazar/ Corresponding Author)
}

\begin{tabular}{|c|c|}
\hline Makale Bilgileri & ÖZ \\
\hline $\begin{array}{l}\text { Makale Geçmişi } \\
\text { Geliş: } 18.06 .2020 \\
\text { Kabul: } 01.10 .2020 \\
\text { Yayın: } 25.12 .2020 \\
\text { Anahtar Kelimeler: } \\
\text { Althaea officinalis-Hatmi } \\
\text { Bitki, } \\
\text { Flavonoid, } \\
\text { Analiz. }\end{array}$ & $\begin{array}{l}\text { Giriş: Geleneksel olarak kullanılan tıbbi bitkiler birçok ilacın geliştirilmesinde ilham kaynağı olmuştur. Hatmi } \\
\text { tıbbi bitkisinin yapılan bilimsel araştırmalara göre yaprak drog'unun özellikle soğuk algınlığı ile birlikte } \\
\text { gözlenen kuru öksürükte antitüssif etki gösterdiği Alman E Komisyonu Monograflarında belirtilmektedir. } \\
\text { Konya yöresinde yetiştirilen Hatmi bitkisinin flavonoid içeriği onun doğru endikasyonda kullanımına yönelik } \\
\text { olup olmadığı konusunda yol gösterici olmaktadır. Flavonoidler antioksidan özellikleri yanında enzimleri } \\
\text { inhibe ederek invitro antibiyotik etki gösterirler. } \\
\text { 'Amaç: Bu çalışma Konya-Akyokuş yöresinde yetiştirilen hatmi bitkisinin çiçeğinin total flavonoid içeriğinin } \\
\text { yeterli olup olmadığını araştırmak amacı ile gerçekleştirilmiştir. } \\
\text { Yöntem: Konya-Akyokuş yöresinde (Temmuz Organik Çiftliğinde } 2017 \text { bahar ayında) yetişen tıbbi hatmi } \\
\text { bitkisinin 100gr. çiçeği kullanılmıştır. Bitkinin \% } \% 0 \text { metanol \%20 su karışımı hazırlanmıştır Tanımlayıcı } \\
\text { kesitsel bir çalı̧madır. Analizler Batı Akdeniz Tarım Orman Bölge Müdürlüğü Tıbbi ve Aromatik Bitkiler } \\
\text { Enstitüsünde yapılmıştır. Numune analizi için gerekli izinler alınmıştır. } \\
\text { Bulgular: Numunemizde Analizi yapılan tıbbi hatmi bitkisinin total flavonoid miktarı } 2,8 \text { mg CE/g olarak } \\
\text { ölçülmüştür. } \\
\text { Sonuç ve Öneriler: Çalışma sonucunda hatmi bitkisinin çiçeğinin total flavonoid içeriği tıbbi kullanım } \\
\text { açısından yeterli bulunmuştur. Hatmi çiçeği ağız, boğaz ve mide mukozalarında irritasyon tedavilerinde } \\
\text { geleneksel olarak kullanılan bir bitkidir. Bu bitkinin ve flavinoit etken maddesinin modern ve geleneksel ve } \\
\text { tamamlayıcı tıpta kullanımına ilişkin ileri çalışmalara ihtiyaç vardır. }\end{array}$ \\
\hline
\end{tabular}

Phytochemical Analysis of Althaea officinalis-Marshmallow Plant Grown in Konya-Akyokuş Region

\begin{tabular}{|c|c|}
\hline Article Info & ABSTRACT \\
\hline Articte nistory & Introduction: Traditionally used medicinal plants have inspired the development of many drugs. According to \\
\hline Received: 18.06 .2020 & the scientific research of the marshmallow medicinal plant, it is stated in the Monographs of the German E \\
\hline Accepted: 01.10 .2020 & Commission that the leaf east has an antitussive effectespecially in dry cough observed with the common cold. \\
\hline Published: 25.12 .2020 & $\begin{array}{l}\text { Objective: To determine if the Althaea officinalis-marshmallow medicinal plant grown in Konya region } \\
\text { contains enough active ingredients. }\end{array}$ \\
\hline Keywords: & Methods: The sample of the sample grown in Konya-Akyokuş region (July Organic Farm). 100gr of medical \\
\hline Althaea officinalis- & marshmallow herb. flower was used. A mixture of $80 \%$ methanol and $20 \%$ water was prepared. The analyzes \\
\hline Marshmallow, & \\
\hline Plant, & edical and Aromatic Plants Institute. Necessary permissions were obtained for sample analysis. \\
\hline Flavonoid & Results: Total flavonoid content of the medicinal marshmallow was analyzed as $2.8 \mathrm{mg} \mathrm{CE} / \mathrm{g}$. \\
\hline Analysis. & $\begin{array}{l}\text { Conclusions and Recommendations: As a result of the study, the total flavonoid content of the flower of the } \\
\text { marshmallow plant was found to be sufficient for medicinal use. Marshmallow flower is a traditionally used } \\
\text { herb for irritation treatments in mouth, throat and stomach mucosa. Further studies are needed on the use of } \\
\text { this plant and its flavinoid active ingredient in modern, traditional and complementary medicine. }\end{array}$ \\
\hline
\end{tabular}

Atıf/Citation: Alp, H. (2020). Konya-Akyokuş yöresinde yetiştirilen althaea officinalis-hatmi bitkisinin etanol extractının toplam flavonoid miktarı, Genel Sağlık Bilimleri Dergisi, 2(3), 159-166. 


\section{GİRIŞ̧}

Fitoterapötik; bitkisel ilaçları nitelemektedir. Etki mekanizmaları bellidir; güvenlik sınırları, yan etkileri, kontrendikasyonları, stabilitesi, toksite sınırları, fizyolojik etkileri bilinen monograflara uygun çağdaş ilaç tanımına uygun ürünlerdir. Farmakopelere uygun bitkinin drog olarak tanımlanmış kısmının standartize edilerek extresi, sabit yağı, uçucu yağı tedavide kullanımını amaçlamaktadır (Zeybek, 2019).

Geleneksel olarak kullanılan tıbbi bitkiler birçok ilacın geliştirilmesinde ilham kaynağı olmuştur (De Sales, 2018). Gastrointestinal hastalıklarda da geleneksel bitkiler tedavi edici olarak kullanılabilmektedir. Dünya Sağlık Örgütü güvenilir tıbbi bitkileri tedavi edici olarak hastalıkların tedavisinde bilimsel olarak önermektedir (Herve, 2018). Birçok tıbbi bitki özleri medikal ilaç yapımında kullanılmaktadır. Önemli bir yan etkisi olmayan kolay temin edilebilen birçok tıbbi bitki mide koruyucu olarak kullanılabilmektedir.

Flavonoidler, polifenoller, terpenoidler (Inas, 2011), saponinler (Awaad, 2013), alkaloitler (De Sales, 2018) ve müsilajın lipolisakaritler (Hage-Sleiman, 2011) dahil olmak üzere şifalı bitkilerden elde edilen doğal ürünler, antiinflamatuar, antimikrobiyal, antiülser, antioksidan ve antikanser gibi büyük farmakolojik öneme sahiptir. Bitki özleri yüksek konsantrasyonlarda bile genellikle güvenlidir. Bitkilerin anti-ülser özellikleri flavonoid (Kumar, 2011; Rao, 2013; Dwivedi, 2013) ve triterpen içerikleri (Pillai, 2010) ile ilişkilendirilebilir.

Polifenoller (esas olarak tanenler ve flavonoidler), anti-enflamatuar, antioksidan ve immünomodülatör özelliklerle ilişkilendirilmiştir. Oksidatif stresi azaltarak polifenoller, iltihaplanma ile ilgili gen ekspresyonunu değiştirebilir, sitokin oluşumunu baskılayabilir (örn., TNF-a ve IL-1) ve doku antioksidan enzimlerini süperoksitdismutaz (SOD) ve düşük glutatyon (GSH) yükseltir (Benchikh, 2018). Fenolik bileşiklerin anti-ülserojenik aktiviteler gösterdiği bildirildi. PG sentezini arttırdıkları için, salgı önleyici etkiler veya sitoprotektif etkiler gibi farklı mekanizmalarla etki ederler (Awaad, 2013). Polifenoller doğal antioksidan bileşikler olarak kabul edilir, çünkü serbest radikallerin neden olduğu doku hasarına karşı ciddi bir koruma potansiyeline sahiptir (Ahmed, 2016). Flavonoidler mast hücrelerinden histamin salgılanmasını azaltabilir ve lipid peroksidasyonunu da inhibe edebilir (Inas, 2011; Awaad, 2013). Ek olarak, flavonoidler mide mukozal glikoprotein parçasını korur ve nitrik oksit (NO) etkisinde bir artışa neden olabilir (Inas, 2011). Tanenler, mukozal zarların ve cildin proteinlerini çökertici büzücü faaliyetlere sahiptir. Bazı tanen türleri mide salgısını baskılamakta ve mukus tabakasını arttırmakta ve mide mukozasını korumak için yerel bir etki göstermektedir (Benchikh, 2018; Bhalke, 2010).

Malvaceae familyasının bir üyesi olan hatmi tıbbi özellikleriyle ünlüdür. Hatminin sulu ekstresinin, lipemi, iltihaplanma, mide ülseri ve trombosit agregasyonunun, tespit edilen advers veya toksik etkiler olmadan tedavisinde potansiyel olarak faydalı olduğu gösterilmiştir (Hage-Sleiman, 2011). Hatmi bitkisi çiçeğinin farmakolojik ve antioksidan aktiviteleri, içeriğinde bulunan polisakkaritler ve flavonoidler gibi çeşitli bileşiklere bağlanmıştır (Talebi, 2014; Fallahpour, 2014). Flavonoid grubu bileşikler ise kalkonlar, aurenler, flavoneller, antosiyanidinler ve antosiyaninlerden oluşmaktadır (Vermerris, 2006). Flavonoidler, antioksidan, antibakteriyel, antiviral, anti-enflamatuar, anti-alerjik, plazmada düşük yoğunluklu lipoproteinleri azaltma, trombosit toplanmasını önleme, serbest radikalleri temizleme ve hücre çoğalmasını önleme gibi çok çeşitli biyolojik etkiler göstermektedir (Spiridon, 2011).

Hatmi tıbbi bitkisinin yapılan bilimsel araştırmalara göre yaprak drogunun özellikle soğuk algınlığı ile birlikte gözlenen kuru öksürükte antitüssif etki gösterdiği Alman E Komisyonu Monograflarında belirtilmektedir. Kök drogu ise yaprak drogu gibi ağız ve boğazın mukoza tahrişlerinde, soğuk algınlığına eşlik eden kuru öksürükte kullanıldığı bilinmektedir. Ek olarak kök drogu mide mukozasının hafif inflamasyon durumlarında da kullanılabileceği belirtilmektedir. Gastrik mukozada koruyucu etkisi nedeniyle peptik ülserlerde kullanılmaktadır. Kök drogunun ayrıca cilt yaralanmalarında ve yanıklarda iyileştirici etkisi bulunmaktadır. Bu amaçla lapa şeklinde stafilokokların neden olduğu karbonkülfronkül vakalarında kullanılabilir (Zeybek, 2019).

Yaprak drogunun içeriği; musilaj ana etkin maddeyi oluşturmaktadır. Yaprakların müsilaj içeriğinin en yüksek olduğu zaman çiçeklenme zamanından hemen önce hasat edilen yapraklar \%6-10 oranında müsilaj içerir. Avrupa Farmakopesine göre şişme indesi 12'den az olmamalıdır. Çözünür polisakkarit karışımları içerir; 
glukagon, arabinogalaktan, glukuronoksilan gibi flavonoid içeriği \%1,4-2,6 arasındadır. Ihlamurda mevcut olan Tilirozid hipolaetin-8-gentiobiosid ve luteolin türevleri olabilir. Müsilaj içeren tıbbi bitkiler mide mukozasını çepeçevre sararak etkin bir koruyucu görevi üstlenirler. Müsilajın visköz özelliği zarar görmüş olan mide mukozasını hızla rejenere eder (Zeybek, 2019).

Kök drogunda müsilaj içeriği \%30’lara kadar çıkabilir. Nötral $\alpha$-glukaganlar, asidik galakturonoramnanlar gibi birçok polisakkarit yapıları içerir. Yoğunluk; hasat zamanı, işlenme yöntemlerinden etkilenebilmektedir. Yıkama, soyma ve kurutma yöntemleri drogun müsilaj miktarını etkilemektedir. Avrupa Farmakopesine göre şişme indisi 12'den az olmamalıdır. Flavonoidler küçük miktarda bulunabilirler sülfatlı olanları da mevcuttur (Zeybek, 2019).

Flavonoidler portakal sarısından sarı renge kadar değişebilen suda çözünen boyar maddelerdir. Flavus kelime anlamı; sarı demektir. İnsan vücudu günlük 50-100 mg flavonoidi gıda maddeleri aracilı̆̆yla alabilmektedir. Yapılarına bağlı olarak geniş bir farmakolojik spektruma sahip olabilmektedir. Antioksidan özellikleri yanında bazı enzimleri inhibe ederek invitro antibiyotik etki gösterebilmektedirler. Flavonoidler en çok brokoli, lahana, soğan, domates suyu, yeşil ve siyah çayda $50 \mathrm{mg} / \mathrm{kg}$ şeklinde bulunmaktadır. Portakal, elma, kiraz, üzüm ve kakaoda ise 10-40 mg/kg miktarında olduğu gösterilmiştir. 6500 kadar flavonoid tanımlanmış olup önceden "vitamin P" olarak isimlendirilmiştir. Bu isimlendirmenin temel sebebi de damar permeabilitesi üzerine antiödematöz etkisinden dolayıdır. $\mathrm{Bu}$ özelliğinden dolayı kapiller direncin bozulduğu diyabet, ateroskleroz, hemorajik hastalıklarda kullanım alanı bulmuştur. Antioksidan etkileri nedeniyle de kozmetik alanında kullanılmasına neden olmuştur. Güneş koruyucu kremlerde uv koruyucu etkisinden dolayı yer almaktadır (Zeybek, 2019). Ayrıca antienflamatuar etkilerinden dolayı prostat karsinomunda brokoli, kolon karsinomunda yeşil çay, tıbbi papatya önerilmektedir. Flavonoidler vücutta gayet iyi tolere edilirler, metabolizmanın basamaklarında yer alırlar, toksite yaratmazlar uzun süre kalmadan da atılırlar. Hatta radyoterapi yan etkilerini azaltmada önerilmektedir. İzoflovanlar, fitoöstrojen grubu olan filavonoitlerdir; üç yapraklı yoncalarda bulunmaktadır. Hatmi bitkisinde flavonoidler dışında da bileşikler bulunmaktadır.

Hem yaprak hem de kök drogunun içerisinde bulunan müsilaj tabakası hassas ve tahriş olmuş mukozada koruyucu etki gösterir. Müsilaj içerisinde bulunan polisakkarit karışımları (galakturonoramnanlar) ekspektoran etki gösterirler, öksürük şiddet ve atak sıklığını azaltırlar. Bu maddeler ayrıca fagositoz artırıcı özellikleri ile de bağışıklık sistemini güçlendirirler. Serbest radikal, lökotrien, proinflamatuar sitokin salınımında artış etkisi daha çok epitel hücrelerinde görülür. Böylece hem yaprak hem de kök drogu polisakkaritleri ve flavonoidleri ile antiinflamatuar etki gösterir. Hatmi tıbbi bitkisinin (Althaea eradix) drogunun ESKOP Monografı da bulunmaktadir (Zeybek, 2019).

$\mathrm{Bu}$ çalışma Konya-Akyokuş yöresinde yetiştirilen hatmi bitkisinin çiçeğinin total flavonoid içeriğinin yeterli olup olmadığını araştırmak amacı ile gerçekleştirilmiştir.

\section{YÖNTEM}

\section{Araştırma Modeli}

Bu çalışma tanımlayıcı türde gerçekleştirilmiştir.

\section{Araştırmanın Evreni ve Örneklemi}

Konya-Akyokuş yöresinde yetiştirilen Hatmi bitkisini çiçeği evreni oluşturmuştur. Temmuz Organik Çiftliğinde yetiştirilen Hatmi bitkisinin çiçeklerinden rastgele alınan 100 gr numune örneklemi oluşturmuştur.

\section{Araştırmanın Uygulanması}

Hatmi bitkisi örnekleri uzman bir eczacı ve fitoterapist (Muammaer Şen) tarafından toplandı. Kültürü yapılmış tıbbi hatmi bitki çiçeği toplu olarak hasat edildikten sonar kurutuldu. Kurutulan bitki ayıklanarak hassas terazi ile 50'şer gramlık paketler halinde paketlendi. Randomize olarak seçilen örneklerden 100gr. BATAM laboratuvarına total flavonoid analizi için gönderildi. 


\section{Verilerin Analizi}

Örneklerin analizi BATAM tarafindan yapılmıştır. Total Toplam flavonoid analizi mg CE/g cinsinden 2 ölçüm yapılarak ortalaması alındı. Alüminyum kompleksi oluşumuna dayalı spektrofotometrik tahlil, gıda veya tıbbi bitki numunelerinde toplam flavonoid içeriğinin belirlenmesi için en yaygın uygulanan prosedürler uyguland1.

\section{Etik Boyut}

Çalışma verilerinin elde eldilmesinde Organik Temmuz Çiftliği ve BATAM laboratuvarının izni ile alınmıştır. Bu çalışma için herhangi bir fon desteği kullanılmamış, araştırmanın bütçesi araştırmacı tarafından karşılanmıştır. Çalışmada her hangibir çıkar çatışması bulunmadığı ve çalışmanın etik boyutuna dikkat edildiğine ilişkin araştırmacı beyanı bulunmaktadır.

\section{BULGULAR}

Analizi yapılan tıbbi hatmi bitkisinin total flavonoid miktarı 2,8mg CE/g olarak bulunmuştur. Bulunan değer hatmi bitkisinin yeterince flavonoid içerdiğini ve uygun dozda ve endikasyonda tıbbi amaçla kullanılabileceğini göstermektedir.

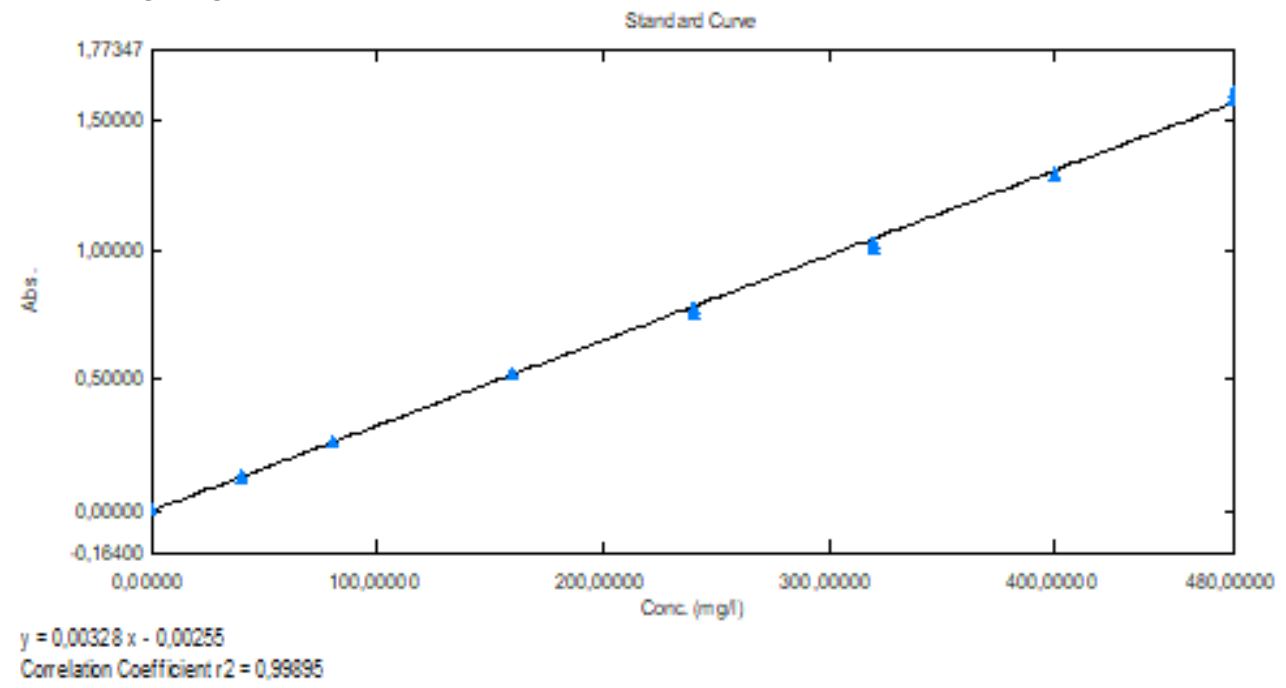

Grafik-1: Hatmi Tıbbi Bitki Flavonoid Absorbans Grafiği

Tablo 1. Toplam Flavonoid Analizi (mg CE/g bitki)

\begin{tabular}{llll}
\hline Numune & 1.ölçüm & 2.ölçüm & Ortalama \\
\hline Tibbi hatmi çiçeği & 2,91 & 2,69 & 2,80 \\
\hline
\end{tabular}

\section{TARTIŞMA}

Tıbbi hatmi bitkisinin flavonoid içeriği hakkında çok fazla çalışma bulunmamaktadır. Tıbbi ve aromatik bitkiler sekonder metabolit içerikleri, yüksek antioksidan aktiviteleri ve diğer bir çok biyolojik aktiviteleri nedeniyle yaygın olarak kullanılmaktadır. Bu bitkilerin metanol, etanol, aseton ve etil asetat gibi çözücülerden elde edilen ekstraktları kullanılarak sekonder metabolit içerikleri ve antioksidan aktiviteleri yoğun bir şekilde araştırılmaktadır. Karataş ve ark. yaptığ bir çalışmada en yüksek flavonoid içeriği ada çayı, limon otu ve yeşil çayda belirlenmiştir (Karataş, 2019). Bu çalışma sonucunda da Hatmi bitkisinin çiçeğinin flavonoid içeriğinin de yüksek olduğu belirlenmiştir.

Flavonoid grubu bileşikler ise kalkonlar, aurenler, flavoneller, antosiyanidinler ve antosiyaninlerden oluşmaktadır (Vermerris,2006). Flavonoidler, antioksidan, antibakteriyel, antiviral, anti-enflamatuar, anti-alerjik, plazmada düşük yoğunluklu lipoproteinleri azaltma, trombosit toplanmasını önleme, serbest radikalleri temizleme ve hücre çoğalmasını önleme gibi çok çeşitli biyolojik etkiler göstermektedir (Spiridon, 2011). Literatürde farklı 
bitkilerin flavonoid içerik ölçümleri görülmektedir.

Inula Viscosa, Akdeniz bölgesi ülkelerinde en çok kullanılan şifalı bitkilerden biridir. Bu çalışmada, iki çözücü (etanol ve metanol) kullanılarak Filistinli Inula viscosa'nın farklı kısımlarının (bütün bitki, yapraklar, saplar ve çiçekler) özütleri elde edilmiş ve Toplam Fenolik İçerik (TPC), Toplam Flavonoid İçeriği (TFC), lipid içeriği 2,2- difenilpikrilhidrazil (DPPH) radikal süpürücü ve antibakteriyel aktiviteler. Sonuçlar, tüm bitki parçalarının Metanolik özütlerinin, etanol kullanılarak elde edilen özütlere göre daha yüksek TPC, TFC ve antioksidan aktiviteye sahip olduğunu göstermiştir (Salim 2017).

Başka bir çalışmada farklı Althea türlerinde kromotografik olarak flavonoid araştırması yapılmış ve incelenen tüm hatmi türlerinin çiçekleri, niteliksel olarak özdeş flavonoid içerdiği tespit edilmiştir. Tiliroside kaempferol 3-0- varlığı glukozit, kersetin 3-0-glukozit, dihidrokaempferol 4'-O-glukozit, naringenin 4'-O-glukozit ve eserhipolaetin 8-0-gentiobioside miktarları onaylanmış. Çiçeklerdeki baskın bileşiklerin tiliroside ve dihidrokaempferol 4'-O-glukozit olduğu görülmüştür (Gudej 1990). Özellikle gıda olarak kullanılan bitkilerin içeriğindeki anti-oksidan, flavonoid içeriklerinin ölçüm teknikleri de önem arzetmektedir.

Sıvı kromatografi-kütle spektroskopisi (LC-MS) gibi gıda, içecek ve bitki özütlerindeki fenolik bileşikleri tanımlamak ve ölçmek için kullanılan son teknoloji tekniklerin yeterli doğruluk veya kesinliğe sahip olup olmadığı tartışılmazdır. Bununla birlikte, bu malzemeleri karakterize etmek ve matristeki toplam fenolik içerik hakkında bir fikir vermek için tarama spektrofotometrik yöntemleri de kullanılabilir (Granato ve ark., 2016). Alüminyum kompleksi oluşumuna dayalı spektrofotometrik tahlil, gıda veya tıbbi bitki numunelerinde toplam flavonoid içeriğinin belirlenmesi için en yaygın uygulanan prosedürlerden biridir (Pekal, 2014).

\section{SONUÇ ve ÖNERILER}

Çalışma sonucunda hatmi bitkisinin çiçeğinin total flavonoid içeriği tıbbi kullanım açısından yeterli bulunmuştur. Hatmi bitkisinin çiçeği ağız, boğaz ve mide mukozalarında iritasyon tedavilerinde geleneksel olarak kullanılan bir bitkidir (Al-Snafi, 2013, Jamian, 2014). Gittikçe tüketimi artan tıbbi ve aromatik bitkilerin yaygın kullanım formundan elde edilen ekstraktlarda söz konusu analizlerinin yapılması günlük kullanım planlarının yapılmasında ve uygun dozda kullanımın sağlanmasında vazgeçilmez bir husustur. Bu bitkilerin doz belirlemeksizin kullanımı sağlık açısında olumsuz sonuçlara yol açabilmektedir. Bu alanda farklı çözücüler kullanılarak yapılan bilimsel araştırmalara insanların yaygın kullanım formu olan sıcak su ekstraktların da dahil edilmesi büyük önem arz etmektedir. Gittikçe tüketimi artan tıbbi ve aromatik bitkilerin yaygın kullanım formundan elde edilen ekstraktlarda söz konusu analizlerinin yapılması günlük kullanım planlarının yapılmasında ve uygun dozda kullanımın sağlanmasında vazgeçilmez bir husustur. Bu bitkilerin doz belirlemeksizin kullanımı sağlık açısında olumsuz sonuçlara yol açabilmektedir. Bu alanda farklı çözücüler kullanılarak yapılan bilimsel araştırmalara insanların yaygın kullanım formu olan sıcak su ekstraktlarında dahil edilmesi büyük önem arz etmektedir.

\section{Finansal destek}

Finansal destek alınmamıştır.

\section{Çıkar çatışması}

Çalışmada çıkar çatışması yoktur.

\section{Teşekkür}

Organik Temmuz çiftliği fitoterapist eczacı Muammer Şen ve BATAM Laboratuvarına bitkinin toplanması ve analizinde geçen emekleri için teşekkür ederiz.

\section{Yazarlık Katkıları:}

Tasarım/Design: H.A.; Veri toplama veya Veri Girişi Yapma/Data Collection or Processing: H.A.; Analiz ve Yorum/Analysis or Interpretation: H.A.; Literatür Tarama/Literature Search: H.A.; Yazma/Writig: H.A. 


\section{KAYNAKÇA}

Ahmed, O.E.I., Hashim, N.M., Ibrahim, M.Y. Abdulrahman, A.A. Adam, H. Arbab, I.A.(2016). Gastroprotectiveeffects of (+)-catechinhydrate on ethanol-inducedgastriculcer in ratsCienc. Tec. Vitivinic. 31, 1-30.

Al-Snafi, A.E. (2013). The pharmaceutical importance of Althaea officinalis and Althaearosea: A review. Int. J. PharmTechRes. 5, 1378-1385.

Awaad, A.S., El-Meligy, R.M., Soliman, G.A., (2013). Natural products in treatment of ulcerative colitis and pepticulcer. J. SaudiChem. Soc., 17, 101-124.

Benchikh, F., (2018). Pharmacological Effects of Myrtus Communis L. on the Gastrointestinal Tract of Ratsand Mice. Ph.D. Thesis, Department of BiologyandAnimalPhysiology, FacultédesSciences de la Nature et de la Vie, Université Ferhat Abbas Sétif 1, Setif, Algeria, 2018.

Bhalke, R.D., Giri, M.A., Anarthe, S.J., Pal, S.C., (2010). Antiulceractivity of the ethanol extract of leaves of Sesbania Grandi flora (Linn.). Int. J. Pharm. Sci. 2, 206-208.

De Sales, I.R.P., Formiga, R.D.O., Machado, F.D.F., Nascimento, R.F., Pessoa, M.M.B. Barros, M.E.F.X. Vieira, G.C. Gadelha, F.A.A.F. Marinho, A.F., Barbosa Filho, J.M., (2018). Cytoprotective, antioxidant and anti-inflammatory mechanism related to antiulceractivity of Cissampelossympodialis Eichl. In animal models. J. Ethnopharmacol, 222, 190-200. doi: 10.1016/j.jep.2018.04.019. Epub 2018 Apr 25.

Dwivedi, S.K., Verma, C., (2013). Potential medicinal plants used as antiulcer agents. Int. J. Pharm. Res. Sci., 2, 885-891.

Fallahpour, F., Banaee, M., Javadzade, N., (2014). Effects of dietarymarshmallow (Althaeaofficinalis L.) extract on growthperformanceand body composition of commoncarp (CyprinusCarpio). Int. J. Adv. Biol. Biom. Res., 2, 2453-2460.

Granato, D., Santos, J.S., Maciel, L.G., Nunes, D.S., (2016). Chemical perspective and criticism on selected analytical methods used to estimate the total content of phenolic compounds in food matrices. TrAC Trends in Analytical Chemistry., 80, 266-279.

Gudej J. Bleganowska ML.(1990). Chromatographic Investigations of Flavonoid Compounds in the Leaves and Flowers of Some Species of the Genus Althaea. Chromatographia, 30, (5/6); 333- 336.

Hage-Sleiman, R. Mroueh, M. Daher, C.F. (2011). Pharmacological evaluation of aqueous extract of Althaea officinalis flower grown in Lebanon. Pharm. Biol. 49, 327-333. doi: 10.3109/13880209.2010.516754.

Herve, E.E. Bernard, G.N. Leandre, K.K. Paul, Y.A. Etienne, E.E. (2018). Acute toxicity and gastric anti-ulceractivity of an aqueous extract of the leaves of MacarangabarteriMll. Arg (Euphorbiaceae) on ratmodels. J. Med. PlantRes. 12, 96-105.

Inas, Z.A. Hala, A.K. Gehan, H.H.(2011). Gastroprotective effect of Cordiamyxa L. Fruit extract against in domethacininduced gastriculceration in rats. Life Sci. J. 8, 433-445.

Jamian, S.S., Mehrani, S., Asilan, K.S., Tabrizi, A.T., Goharian, A., (2014). Responses of seedling growth and germination parameters in three medicinal plants under drought stress. Int. J. Agric. Crop. Sci., 7, 191-195.

Karataş, İ., Karataş, R., Elmastaş, M., (2019). Yaygın olarak kullanilan bazi tibbi ve aromatik bitkilerin sicak su infüzyonlarinin sekonder metabolit içeriği ve antioksidan aktivitelerinin belirlenmesi. Gaziosmanpasa Journal of Scientific Research.8(2); 49-52.

Kumar, M.R., Niyas, M.K., Mani, T.T., Rahiman, O.M.F., Kumar, S.B., (2011). A review on medicinalplantsforpepticulcer. Pharm. Lett. 3, 414-420.

Pekal, A. \& Pyrzynska, K., (2014). Evaluation of Aluminium Complexation Reaction for Flavonoid Content Assay. Food Anal. Methods, 7, 1776-1782.

Pillai, S.I., Kandaswamy, M., Subramanian, S., (2010). Antiulcerogenic and ulcer healing effects of Indian propolis in experimental rat ulcer models. J. Api. Prod. Api.Med. Sci., 2, 21-28.

Rao, C.V., Venkataramana, K., (2013). A pharmacological review on natural antiulceragents. J. Glob. TrendsPharm. Sci., 4, $1118-1131$.

Salim, H., Rimawi, W.H., Mjahed, A., (2017). Analysis of extracts from palestinian inula viscosa for their phenolic, flavonoid and lipid contents, antioxidant and antibacterial activity. Journal of Chemistry and Biochemistry, 5(1), 12-23. http://scholar.ppu.edu/handle/123456789/455.

Spiridon, I., Bodirlau, R., Teaca, C.A., (2011). Total phenolic content and antioxidant activityof plants used in traditional Romanian herbal medicine. Cent. Eur. J. Biol., 6(3), 388-396.

Talebi, A., Karimi, A., Ouguerram, K., Vahidi-Ataabadi, N., Eshraghi-Jazi, F., Mansouri, A., Nematbakhsh, M., (2014). Lack of nephroprotective efficacy of althaea officinalis flower extract against gentamicin renal toxicity in malerats. Int. J. Prev. Med.., 5, 1360-1363.

Vermerris, W., Nicholson, R., (2006). Phenolic Compound Biochemistry. s. 1-32.

Zeybek AU, Özgüç S (2019). Mide Hastalıklarında Fitoterapi. Modern ve Rasyonel Fitoterapi. 1.baskı Dünya tıp kitapevi. Ankara.p.99-101. 


\section{EXTENDED ABSTRACT}

Introduction: Traditionally used medicinal plants have inspired the development of many drugs. According to the scientific research of the marshmallow medicinal plant, it is stated in the Monographs of the German E Commission that the leaf east has an antitussive effectespecially in dry cough observed with the common cold. Phytotherapeuticals; qualifies herbal remedies. Its mechanisms of action are clear; They are products suitable for the definition of modern drugs in accordance with monographs whose safety limits, side effects, contraindications, stability, toxicity limits, physiological effects are known. It aims to standardize the part of the plant suitable for pharmacopoeia as drog by using standardized extrusion, fixed oil and essential oil in the treatment. A member of the Malvaceae family, marshmallow is famous for its medicinal properties. Aqueous extract of marshmallow has been shown to be potentially beneficial in treating lipemia, inflammation, stomach ulcer and platelet aggregation without detected adverse or toxic effects (Hage-Sleiman, 2011). The pharmacological and antioxidant activities of the marshmallow flower have been linked to various compounds such as polysaccharides and flavonoids (Talebi, 2014; Fallahpour, 2014). Flavonoid group compounds are composed of chalcones, aurenes, flavonelles, anthocyanidins and anthocyanins (Vermerris, 2006). Flavonoids show a wide variety of biological effects such as antioxidant, antibacterial, antiviral, anti-inflammatory, anti-allergic, low-density lipoproteins in plasma, preventing platelet aggregation, scavenging free radicals, and preventing cell proliferation (Spiridon, 2011). Flavonoids are water-soluble dyes that can range from orange yellow to yellow color (flavus means yellow). The human body can take 50$100 \mathrm{mg}$ of flavonoids daily through food. Depending on their structure, they can have a wide pharmacological spectrum. In addition to their antioxidant properties, they can have an in vitro antibiotic effect by inhibiting some enzymes.

Objective: To determine if the Althaea medicinal plant grown in Konya region contains enough active ingredients.

Methods: Althaea officinalis plant samples were collected from Konya-Temmuz Organic Farm. The analyzes were performed in the Laboratory of Medical Aromatic Plants Center of West Mediterranean Agricultural Research Institute. Necessary permissions were obtained for sample analysis. This study was conducted in a descriptive manner.

A mixture of $80 \%$ methanol and $20 \%$ water was prepared.

Total Flavonoid Quantity Determination

Flavonoid amount was used by making small changes in Pekal and Pyrzynska (2014) method (19). The amount of flavonoids was determined as equivalent to mg quercetin (mg KUE / g) using the calibration chart.

$1 \mathrm{ml}$ of extract, $4 \mathrm{ml}$ of distilled water, $0.3 \mathrm{ml}$ of $5 \%$ NaNO2 are added and mixed, after $5 \mathrm{minutes}, 0.6 \mathrm{ml}$ of $10 \%$ $\mathrm{AlCl} 3.6 \mathrm{H} 2 \mathrm{O}$ is added, after 5 minutes, $2 \mathrm{ml}$ of $1 \mathrm{~mol} / \mathrm{L} \mathrm{NaOH}$ is added, total volume is completed to $10 \mathrm{ml}$ with distilled water,

After mixing the mixture well, the spectrophotometer is read at $510 \mathrm{~nm}$ wavelength and the total amount of flavonoids is calculated by using the absorbance value and the curve prepared with catechin.

Results: The total flavonoid amount of the medical marshmallow plant analyzed was found to be $2.8 \mathrm{mg} \mathrm{CE} / \mathrm{g}$. The value found indicates that the marshmallow herb contains enough flavonoids and can be used for medicinal purposes in appropriate doses and indications. Karataş et al. In his study, the highest flavonoid content was determined in sage, lemongrass and green tea (Karataş, 2019). As a result of this study, it was determined that the flower of the Marshmallow plant also has high flavonoid content.

Conclusions and Recommendations: There are not many studies on the flavonoid content of the medicinal marshmallow plant. Medicinal and aromatic plants are widely used due to their secondary metabolite content, high antioxidant activities and many other biological activities. Secondary metabolite contents and antioxidant activities of these plants are extensively investigated using extracts obtained from solvents such as methanol, ethanol, acetone and ethyl acetate. Karataş et al. In his study, the highest flavonoid content was determined in sage, lemongrass and green tea (Karataş, 2019). Inula Viscosa is one of the most used medicinal plants in the countries of the Mediterranean region. In this study, extracts of different parts of Palestinian Inula viscosa (whole plant, leaves, stems and flowers) were obtained using two solvents (ethanol and methanol) and Total Phenolic Content (TPC), Total Flavonoid Content (TFC), lipid content 2, 2diphenylpicrylhydrazyl (DPPH) radical scavenging and antibacterial activities. The results showed that Methanolic extracts of all plant parts had higher TPC, TFC and antioxidant activity than extracts obtained using ethanol (Salim 2017). In another study, flavonoids were investigated chromatographically in different Althea species, and the flowers of all examined marshmallow species were found to contain qualitatively identical flavonoids. The amounts of kaempferol 3-0- glucoside, quercetin 3-0-glucoside, dihydrokaempferol 4'-O-glucoside, naringenin 4'-O-glucoside and 8-0 gentiobioside in tiliroside were approved. It has been observed that the dominant compounds in flowers are tiliroside and dihydrokaempferol 4'-Oglucoside (Gudej 1990). Measurement techniques of anti-oxidant and flavonoid contents of plants used as food are also important.

As a result of this study, it was determined that the flower of the Marshmallow plant also has high flavonoid content. Althaea officinalis is a plant traditionally used in irritation treatments in mouth, throat and gastric mucosa (Al-Snafi, 2013; Jamian, 2014). The flower of the medical marshmallow plant is mostly used in folk medical culture in middle eastern medicine. The flower of the plant contains many vitamins, bioflavonoids, antioxidant compounds (Fallahpour, 2014). It is an 
indispensable issue in the daily use plans of the extracts obtained from the widespread use form of the medicinal and aromatic plants, which are increasing in consumption, and in ensuring the proper use of the dosage. In this field, it is very important to include hot water extracts, which are the common form of use of people, in scientific researches using different solvents. As a result of the study, the total flavonoid content of the flower of the marshmallow plant was found to be sufficient for medicinal use. Marshmallow flower is a traditionally used herb for irritation treatments in mouth, throat and stomach mucosa. Further studies are needed on the use of this plant and its flavinoid active ingredient in modern, traditional and complementary medicine. 